\title{
Assessment of the Research Learning Needs of University of Saskatchewan Librarians: A Case Study
}

\section{Alvin M. Schrader, Ali Shiri, and Vicki Williamson}

\begin{abstract}
As academic librarians with faculty status increasingly embrace research engagement as a core value and requirement, one of the little-studied questions is the extent to which they possess the requisite knowledge and skills to conduct high-quality research and scholarship and what further learning needs they might have within the organizational setting. This paper summarizes an institutional case study of the research knowledge of academic librarians employed at the University of Saskatchewan, encompassing their current research interests, experiences, competencies, environmental context, and learning needs. The goal was to develop a framework for additional educational activities and institutional supports that would enhance their knowledge and skills.
\end{abstract}

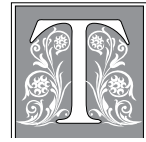

he University Library at the University of Saskatchewan presents itself at the forefront of research leadership in academic librarianship in Canada, with arguably the most demanding standards of research expectations for librarians in the country. Accordingly, the university library's present vision, in close alignment with the knowledge-intensive mission of its parent institution, is to increase significantly the profile of its librarians as researchers and embrace research engagement as a core professional and institutional value.

As University of Saskatchewan librarians continue to embrace research engagement as a core value and take on the challenge of producing and disseminating both scholarly and applied research knowledge, it is important that their research skills are systematically developed and augmented. Research excellence depends on continuous enhancement of expertise and on close engagement with the cutting edge of scholarship, at both theoretical and methodological levels. Concomitantly, appropriate institutional supports to foster this development are also needed.

This article describes a case study snapshot of one initiative among many in this institution's response to advancing its vision. The article summarizes the findings of a Web-enabled questionnaire survey designed, in conjunction with

Alvin M. Schrader is Director of Research for University of Alberta Libraries, Professor Emeritus, University of Alberta, and former Director and Professor in the School of Library and Information Studies at the University of Alberta; e-mail: alvin.schrader@ualberta.ca. Ali Shiri is Associate Professor in the School of Library and Information Studies at the University of Alberta; e-mail: ali.shiri@ualberta.ca. Vicki Williamson is Dean, University Library, University of Saskatchewan; e-mail: vicki.williamson@usask.ca. (C) Alvin M. Schrader, Ali Shiri, and Vicki Williamson. Attribution-NonCommercial (http://creativecommons. org/licenses/by-nc-sa/3.0/) CC BY-NC 
other investigative strategies, to shed light on the research learning needs of academic librarians employed by the University of Saskatchewan. The goal of the survey was to provide evidence that would facilitate development of an institutional framework for planning activities and programs designed to enhance the knowledge and skills of librarians as faculty about the various components of research and scholarly communication.

Survey data revealed that University of Saskatchewan librarians are active and committed researchers, engaged in diverse forms of scholarly activity and pursuing research programs in a wide variety of areas. Two-thirds of participating librarians said they were involved in research at the time of the survey, and more than 90 percent had plans to complete a research project within the next year or two. Many respondents commended the university library for the existing range of research supports designed to foster further research and promote an institutional climate of research and scholarly work. They also offered a plethora of ideas for enhancing research activities, research engagement, and the research culture.

\section{Background and Framework \\ The Climate and Culture of Research and Scholarship in Academic and Research \\ Libraries}

Research is a process of inquiry that depends on expertise, engagement with the cutting edge of scholarship in specialized disciplines or interdisciplines... One aspires to be in ongoing contact and synergy with a network of peers who are defining and redefining the parameters of knowledge... In order to be effective in creating an environment of research excellence, we need to know that our research is supported by the institution in which we work, that its excellence is recognized to arise from our commitment to excellence.-Regna Darnell (2009) ${ }^{1}$
The practice of academic research and research leadership involves the many interconnected challenges of foundational competence, tacit knowledge gained through the experience of academic research apprenticeship, continuous learning about critical bodies of research literature, broad collegiality and networking for research awareness and peer dialogue, beneficial research productivity, and, with rare exceptions, extensive institutional investment. As psychology professor Ellen Bialystok said in a recent Globe and Mail interview with Elizabeth Church (2010), the real art of research is "knowing how to stay on the path and follow the evolution of an idea through all of its twists and turns. When we look at a research finding as a breakthrough, for the person who found it, it is anything but a breakthrough. It is years of tedious small steps." 2

Applied research practitioners and policy research analysts face the further challenge of transforming research knowledge into real-life service innovations through the intertwined filters of existing institutional and professional values, goals, policies, and practices; in the classic dictum, ends must justify means. The incorporation of research into daily work is little-charted territory, causing considerable uncertainty among practitioners. The challenge of transformative applications explains why research-developmentpractice gaps are experienced in terms of years and often decades.

To succeed, librarians as faculty recognize the challenges involved in producing and disseminating both scholarly and applied research knowledge. However, given the larger context described above, it is critical that the research skills gap between expectations and competencies be addressed and that research skills are systematically developed and augmented. However, given the larger context described above, it is critical that the research skills gap between expectations and competencies be addressed and that research skills are systematically 
developed and augmented. Advancement in both theory and methodology depend on continuous enhancement of research knowledge and expertise. In passing, it might be noted that the 2010-2012 strategic plan of the Canadian Association of Research Libraries (CARL), the leadership organization for the Canadian research library community, calls on the Association to "work to develop research skills in research libraries and to promote evidence-based librarianship"; and, more recently, CARL published a new model "Core Competencies for 21st Century CARL Librarians," which addresses research and professional contributions as a key component of practitioner expertise. ${ }^{3}$

Vicki Williamson (2010) undertook an informal questionnaire survey of academic librarians' faculty status and publishing requirements within the 29 members of CARL. ${ }^{4}$ Among the 19 responding institutions $(66 \%)$, the survey found that 14 $(73 \%)$ had faculty status (although it was noted by one respondent that librarians had faculty status but not tenure). On the question of publishing requirements for tenure and promotion, responses were almost evenly split, with only 9 institutions, or 47 percent, in the affirmative, including three who added that their criteria were "broadly defined" and another who said, "where approved by the library." At the same time, even among the 10 institutions who said there were no publishing requirements, six mentioned that publishing was "considered but not required." Only the University of Saskatchewan reported an unqualified requirement for peer-reviewed publication.

Moreover, the Canadian Association of University Teachers (CAUT) affirms the integral role that university and college librarians play in the pursuit and dissemination of knowledge, with full entitlement to academic freedom: "CAUT believes that academic librarians are full partners with faculty members in the scholarly and intellectual functions of universities and colleagues." ${ }^{5}$ In its "Model Clause on the Scholarly Activities of Academic Librarians," the association states that: "A librarian shall have the right to devote up to $40 \%$ of normal workload to the pursuit of research, study, educational and other scholarly activities"; and that these activities are to be considered in performance appraisal, promotion, and tenure evaluation. ${ }^{6}$

\section{The University Library, University of Saskatchewan: A Case Study of Research Climate and Culture}

The broad understandings of the complexities of research culture described earlier form the tacit framework for developing effective institutional policies and practices to support research and scholarly work at the University of Saskatchewan. For the University Library at the University of Saskatchewan, this framework is further informed by the special circumstances of librarians as faculty that are unlikely to characterize faculty colleagues in other colleges at the University of Saskatchewan, namely, that the master's degree in library and information studies (almost exclusively course-based and with no research component other than an introductory course in social science research, if that) is the credential required for the librarian profession.

Moreover, until quite recently, the practitioner service model largely overshadowed the research culture model in Canadian academic librarianship. As a result, few librarians have undergone intensive research learning as experienced by other faculty through the research apprenticeship model that dominates academic culture. The consequence is that a culture of research engagement within the broader profession of academic librarianship is only gradually emerging at the present time. Daphnée Rentfrow (2008) has written about faculty perceptions of librarians and their educational qualifications:

If librarians are to convince faculty that they are their intellectual 
equals, then the degree cannot be simply a vocational one. What is needed for the research library of the future are librarian-scholars prepared and trained by degree programs that require rigorous scholarship, publication, and teaching as part of the training. ${ }^{7}$

With arguably the most demanding standards of research expectations among academic libraries in Canada, the University Library at the University of Saskatchewan is at the forefront of national research leadership in academic librarianship. The university library's present vision is to increase significantly the profile of its librarians as researchers and to embrace research engagement as a core professional and institutional value. This vision is, accordingly, closely aligned with the knowledge-intensive mission of its parent institution.

The need for the research presented in this article was identified as a strategic and organizational imperative through the university library planning processes. The library's 2009 strategic plan recognizes the importance of providing support to librarians as researchers and innovators in pursuit of the institutional vision to develop a strong research program. An important action item advancing that vision called for an assessment of the research learning needs of librarians as faculty and was intended to lay the groundwork for two later planning cycle action items: one, identifying the "signature research themes" of librarians as researchers; and the other, developing an implementation plan to meet identified needs. ${ }^{8}$

These and several completed projects support one of the university library's core strategies, the Researcher, Scholar, Practitioner Strategy, part of which mandates librarians as faculty to intensify their research efforts and productivity. The library's collective and shared vision of the critical value and importance of research in the practice of professional skills is closely aligned with a key priority in the university's current strategic plan to enhance its profile in research, scholarly, and artistic work. ${ }^{9}$

Key milestones achieved in the three years prior to the research needs assessment were the following initiatives:

- assignment of scholarly communication initiatives to a librarian;

- restructuring university library duties and workflows to support librarians' research activities, as stipulated in the Guidelines for the Assignment of Duties, which specify that tenured librarians devote 15 percent of their time to research and scholarship and pretenure librarians 20 percent, with the possibility of assignments of up to 100 percent for specific periods prior to consideration for renewal or tenure;

- refocusing the Librarians' Forum to include a research component;

- the listing of librarians' research output (at last count, 131 items consisting of 70 peer-reviewed articles, 29 conference presentations, and 32 other items ) on eCommons@USASK;

- establishing the Dean's Research and Innovation Fund to provide financial support to librarians to conduct research that advances a defined program of research and scholarship, or to pilot and implement innovative projects that link to the library's strategic priorities;

- initiating the Dean's Research Lecture Series to recognize librarians as researchers and to help raise the profile of research in the discipline and in the larger academic and professional communities at large; and

- adopting the Dean's Guidelines on Educational Support for Librarians Pursuing Doctoral Qualifications to grow research capacity and capability in realizing the library's vision of developing a strong research program.

Other initiatives have included the insertion of a statement of research and scholarship expectations into position announcements for tenure-track librarians; an all-day introductory workshop on research methods conducted by Dr. 
Joan Giesecke, Dean of Libraries and Professor, and Dr. Nancy Busch, Associate Dean and Professor, both of the University of Nebraska-Lincoln, in 2008; and, a workshop on approaching publishers. Also active is the Pre-Tenured Librarians Group (PTLG), an informal venue for discussion of a range of issues including research and tenure processes.

The university library is considered a nondepartmentalized college with an academic and service mission within the University of Saskatchewan and subject to academic standards for tenure and promotion similar to those governing faculty performance in the teaching colleges. Accordingly, the research component of the 2009 strategic plan supports the expectation of scholarly work by librarians as faculty. This component is articulated in Section 5.2 Scholarly Work in the University of Saskatchewan Library Standards for Promotion and Tenure (see Appendix A). The university provides Guidelines for Preparation of Case Files for Renewal of Probation, Tenure, and Promotion, and the university library provides a Web-based CV template for librarian applications. Quality and significance of scholarly work, together with a programmatic approach to research engagement, are noted as evaluative criteria in the standards for tenure and promotion and in the Guidelines for the Assignment of $\mathrm{Du}$ ties. There is an annual review of progress through the ranks (Librarians I, II, and III) toward meeting formal standards; progress through ranks is based primarily on research and professional expectations - not on organizational hierarchy and supervisory responsibilities.

\section{Literature Review}

It is a truism to point out how extensive the professional literature is on the status of academic librarians, dating as far back as 1878 according to Jacalyn E. Bryan (2007), ${ }^{10}$ with suggestions for tenure as early as 1911 though not officially endorsed until 1946. ${ }^{11}$ However, much of this literature is anecdotal, impres- sionistic, self-promotional, and exhortatory rather than empirical and analytical. Much of it dwells on faculty rights and privileges rather than on equivalent responsibilities and performance obligations. As Donald E Riggs (1999) advised those interested in an academic library career with faculty status equivalent to nonlibrarian teaching faculty, "If they do not want the responsibilities that go with faculty status, they should look for employment in an academic setting that does not require such." ${ }^{12}$ In a general review of the issue, Bryan pointed out that the faculty status option has the support of three major associations - the Association of College and Research Libraries (ACRL), the American Association of University Professors, and the Association of American Colleges and Universities ${ }^{13}$ - with similar endorsements in Canada by CARL and CAUT, as mentioned above.

Commitment to a culture and climate of research and scholarship among academic librarians is two-pronged, with factors touching both institutions and professionals. In the older tradition of the scholar-librarian but now recontextualized in new modes of evidence-based work and applied research, academic librarians have long advocated for faculty status. In 1958, the Committee on Academic Status was established by ACRL and was the first to endorse formally faculty status. ${ }^{14}$ In 1971, ACRL formally adopted standards for faculty rank, status, and tenure for librarians, and subsequent documents have elaborated professional concerns to address work responsibilities, peer review, library governance, compensation, leaves and research funding, and academic freedom. ${ }^{15}$ In 2010, ACRL issued guidelines for appointment, promotion in academic rank, and tenure of academic librarians, with criteria for probationary appointment, termination, grievance, dismissal, and academic freedom and protection against discrimination. ${ }^{16}$

Beyond the literature on faculty status and related matters, Deborah B. Henry and Tina M. Neville (2004) found that 
there is a growing body of empirical research into academic librarians' publication patterns and expectations, either national in scope, at the state level, or focused on specific populations such as health science librarians. ${ }^{17}$

One of the little-studied questions, however, is the extent to which academic librarians possess, and perceive themselves to possess, the requisite knowledge and skills to conduct high-quality research and scholarship and what further learning needs and institutional supports would help them maintain and enhance their productivity. Paul Alan Wyss (2010) noted that debate has focused on the requisite terminal degree for academic librarians, with some writers asserting that the typical master's degree in library and information studies (MLIS) provides an inadequate foundation for scholarly pursuits. ${ }^{18}$ In a study of the perceptions of library school faculty about faculty status for academic librarians, respondents said that they did not consider that the MLIS degree offered sufficient preparation for faculty status and that courses on statistics and research processes should be required.${ }^{19}$ Nonetheless, at the turn of the 21st century, only half of the accredited MLIS programs required an introductory course in research methods, and four U.S. schools did not even offer an elective in it (Schrader 2003). ${ }^{20}$

Descriptive data on research competencies and competency gaps are not widely reported, nor are methodologies for capturing and articulating deeper insights into prevailing attitudes and perspectives regarding the research and scholarship enterprise. Three recent studies have addressed particular aspects of interest to the present study, those by Joseph Fennewald (2008), ${ }^{21}$ David Fox (2007, 2007), ${ }^{22}$ and Alvin M Schrader (2010, 2011). ${ }^{23}$ In a sort of institutional case study, Fennewald held face-to-face interviews with academic librarians at Penn State to shed light on their perceptions of research productivity and barriers. Fox conducted a Web-based questionnaire survey of the motivations of Canadian academic librarians to engage in research and scholarly activities, the perceived importance of such activities as a criterion for tenure and promotion, and the availability of various types of support.

In a study that served as a precursor to the University of Saskatchewan assessment project, Schrader, in collaboration with colleagues Kathleen De Long, Allison Sivak, and Diane Clark, surveyed the current levels of research knowledge, experience, interests, competencies, and learning needs of academic librarians at the University of Alberta Libraries (UAL), which serves faculty, staff, and students at one of the largest research-intensive universities in Canada; the UAL survey instrument was used as a template for developing and refining the University of Saskatchewan approach. In a study identified too late to inform our own work, Phillip M. Edwards, Elaine Z. Jennerich, and Jennifer L. Ward (2009) reported on a collaborative project between the University of Washington Libraries at Seattle (UW Libraries) and the Information School (iSchool), University of Washington, to "foster a culture of research, increase the visibility and prestige of the UW Libraries, build partnerships with other organizations, support applied research for strategic decision-making, and bolster organizational outcomes based on research findings." One initiative was a needs assessment survey of UW librarians and professional staff, conducted in 2004, to identify a variety of research knowledge and skills barriers, together with institutional barriers to conducting research. Issuing from the survey and follow-up discussions was a series of programs focusing on institutional support mechanisms, educational workshops, a poster sessions event showcasing four projects, and two social events involving iSchool doctoral student presentations. ${ }^{24}$

A similar Web-based survey is currently being conducted by Kristine Brancolini and Marie Kennedy, ${ }^{25}$ based in part on the needs assessment by Edwards, Jennerich, 
and Ward (2009) described above as well as on a survey by Henry and Neville, ${ }^{26}$ to learn how respondents assess their own "skills in completing discrete tasks related to research projects" and to examine institutional support for research endeavors, with a view to informing "the curriculum of a proposed continuing education opportunity for librarians in an academic setting." ${ }^{27}$

\section{Research Questions}

The immediate goal of this research was to gain a better understanding of the research knowledge of University of Saskatchewan librarians encompassing their research interests, research experiences, research competencies, and research learning needs. Key survey questions were:

- Are you currently involved in a research project, and if so, do you have any funding support?

- What research and dissemination plans do you have?

- What recent research experience have you had?

- How would you describe your own knowledge of research and the research process, and is it important to you to increase your knowledge in particular areas?

- Which institutional supports already in place are helpful, and what more is needed to foster further research and promote an institutional climate of research and scholarly work?

- Which delivery mode(s) do you prefer for more research knowledge acquisition?

These questions focused on various components of research and scholarly communication, broadly encompassing areas such as grant and proposal development, ethics review, peer review, survey methodology, data collection, data analysis, interpretation, journal article writing, and presentation skills. Additional questions concerned collaborative research arrangements, mentoring programs for research engagement, and the types of research supports the university library should provide to promote a culture of research and scholarly work.

To date, only an impressionistic sense was available to the university library and the broader academic community of how active librarians are in research and scholarship. Accordingly, it was anticipated that insights thus gained would facilitate the development of a framework for planning activities and programs that would enhance the research knowledge and skills of librarians as faculty about the various components of research and scholarly communication. It was suggested that an enhanced culture of research and scholarly engagement would ultimately serve the broader goals endorsed and promoted by the university library of library user service policy and program improvements, evidence-based practice, and institutional accountability.

\section{Methodology}

Primary data collection in this case study of one institution involved a confidential, anonymous, Web-enabled questionnaire survey (Appendix B) using the SurveyMonkey software, with a target population consisting of the cohort of tenured and tenure-track faculty (librarians) employed by the University of Saskatchewan, totaling 40 eligible respondents at the time of the survey. Ethics clearance for this research was sought through the Behavioral Research Ethics Board at the University of Saskatchewan and categorized by the Board under the category of "quality assurance" research.

The survey benefited from a Webbased questionnaire survey conducted by Fox (2007a, 2007b), described earlier, of the motivations of Canadian academic librarians to engage in research and scholarly activities, the perceived importance of such activities as a criterion for tenure and promotion, and the availability of various types of support. In turn, the survey benefited from the University of Alberta study reported by Schrader (2010, 2011), which surveyed the current 
levels of research knowledge, experience, interests, competencies, and learning needs of UAL librarians; the UAL survey instrument was used as a template for developing and refining the University of Saskatchewan approach. In both the UAL and the Saskatchewan surveys, the practice of capturing rich narrative data was followed; this was done by consistently inviting open-ended commentary following each survey question, so that participants could communicate in their own words and phrasings.

The survey also benefited from a variety of onsite meetings: discussions with key university and university library officials for gathering policy insights, contextual information, and feedback; meetings with the Librarians' Forum and the Pre-Tenured Librarians Group to explain the study, describe ethical considerations, answer questions, gather information, and explore librarians' concerns and issues; informal discussions with two librarians at their request; and interviews with two librarians about their recent experience in conducting and publishing a research project, following a modified template that was first developed by Fennewald (2008) in his study of the research productivity of campus librarians. These meetings together served to provide valuable background context for the survey.

The questionnaire survey was field tested, with only two minor points of feedback, and distributed on the university library intranet. Prospective participants were invited to participate in the Web-enabled survey between April 20 and April 30; during this period, three follow-up reminders were issued, and the survey deadline was extended by one week to maximize participation. Of the 40 librarians (including four on leave) eligible to participate, $30 \mathrm{did}$ so, for an excellent response rate of 75 percent of the target population. Collected data were reviewed and edited for anonymity. Qualitative narrative comments were analyzed for concepts and themes, and for their frequencies; comments to illustrate common ideas, topics, and viewpoints were selected for reporting here.

\section{Findings}

Survey data revealed that University of Saskatchewan librarians are active and committed researchers, engaged in diverse forms of scholarly activity and pursuing research programs in a wide variety of areas. Two-thirds of participating librarians said they were involved in research at the time of the survey, and more than 90 percent indicated plans within the next year or two to complete a research project and share findings through publication or conference presentations; several new librarians, however, expressed difficulty in articulating a clearly defined program of research.

Respondents' research experiences in the previous two years were diverse. More than half had published a journal article or presented at a conference, and one-third had organized a conference. Some 20 to 25 percent had written a research grant proposal, presented a conference poster, published in other digital forms, reviewed a book, refereed journal articles, or edited a journal. Respondents also mentioned writing for conference proceedings, publishing a book, writing a book chapter, editing conference proceedings, writing evidence summaries, writing professional articles and columns, and writing internal research reports.

About half of the respondents identified one, and sometimes two, sources of financial support for their current research activities. Most frequently mentioned were the New Faculty Start-up Grant, the Dean's Research and Innovation Fund, the Research Acceleration Program Grant, and the Dean's educational support for doctoral studies. Other sources of research support were Health Canada, the Office of the Privacy Commissioner, and the President's Committee on Integrated Planning. Two respondents said research was part of their professional practice, and one of them also referred to their professional expense account. Another re- 
ported working as a co-investigator with a teaching faculty member to develop a major SSHRC application.

Participating librarians identified a wide range of research programs and areas of research interest:

- Health sciences librarianship (4 librarians): student information-seeking behaviour, instruction;

- Veterinary medicine librarianship (2 librarians): consumer health information for pets, library instruction for vet students, veterinary medicine literature;

- Evidence-based librarianship (2 librarians): use in practice, theoretical underpinnings;

- History (2 librarians): local, American and Canadian;

- Bibliometrics (2 librarians);

- Information literacy (2 librarians): library instruction;

- Digital collection development (2 librarians): e-books;

- Scholarly communication (2 librarians): in the sciences, open science;

- Open access publishing and archiving;

- Technology impact on librarian professional practice;

- Relationship/merging between physical and digital worlds in relation to libraries;

- E-resources access and security: unauthorised use of e-resources;

- Serials collection management best practices, user access;

- Digital government publications: collection, organization, preservation and use, including discovery, access, and use with general Personal Information Management/Personal Knowledge Management tools, literature collection on digital books as one facet of digital government publications;

- Special collections discovery and access issues: digitization, online exhibitions, ILL concerns;

- Print collection preservation, especially collaborative preservation;

- Humanities computing;

- Information architecture;
- Spatial issues in new media;

- Undergraduate internships in academic libraries;

- Student engagement and student social, active, and informal learning processes and activities;

- Reference and information services, especially collaborative approaches rather than referral service focus;

- Geographic information systems;

- People in the information profession, including education for librarianship, leadership, human resources management;

- Archives and public policy: privacy legislation, generational perceptions of privacy and archival interpretation of privacy in collections, archivist and funder perceptions of the value of archives to society;

- Knowledge-based economy/society public policy, especially infrastructure in support of innovation and knowledge transfer, literature collection on such infrastructure; and Organizational culture: work environment impact, collaboration in higher education, models/framework for promoting collaboration between academic and nonacademic units.

While participating librarians reported considerable research experience, a key finding was that half or more of the respondents identified six specific areas in which they wanted to increase their knowledge about research, prioritized as follows:

- analyzing data,

- choosing methodology,

- formulating a problem statement or research question,

- publishing findings, including writing an article for a refereed journal,

- writing a research proposal, and

- grantsmanship: finding sources and writing grant proposals.

Lower -ranked areas, mentioned by some 20 to 40 percent of respondents, were the following aspects of the research process: critical review of literature; peer reviewing, refereeing conference and article submissions; ethics clearance; presenting findings at a conference or workshop; 
writing a technical report; and preparing a poster presentation for a conference or workshop. A few respondents indicated more specific needs: gaining a better understanding of the domain and the nature of library research questions and topics; adjusting to research methodology in progress; and finding effective ways of approaching publishers. Several respondents shared their uncertainty about how to carry out research and analyze data, explaining they were relatively new to librarianship, had switched research areas and methodologies, did not have very much research experience, or did not enjoy writing. One respondent observed that research methods "seem to be easier in theory than in actual practice, and while I guess practice makes (somewhat) perfect, it would be good not to feel so shaky about them going into a research project." Another wrote: "Lost... there are so many pathways that I can pursue... some are based on experience, some out of passion, some out of interest and others just out of curiosity." Suggested "refreshers" were the overall research process, methodologies in general and interviews and surveys in particular, statistical analysis, workflow, and data analysis.

Another key finding in this study almost as important as the identification of specific research learning needs related to pedagogical preferences: how participating librarians want to learn more about these research areas and components. Respondents thought that the best delivery modes by far for research knowledge enhancement would be in-person workshops and seminars, one-on-one consultation, mentoring and coaching, and reading. Mentioned less frequently (three or fewer times) were Web-based prepackaged tutorials, courses, and workshops; real-time formal courses, perhaps for credit; small research teams; and attending conferences.

Many respondents noted the importance of both active learning modes and access to information at point of need: “experience by doing" under expert guid- ance; "hands-on" sessions with projects already in development; workshops with follow-up discussion or even with assignments; and having guidance and resources available at critical points in the research process. One librarian noted that "just in time" is better than "just in case." Another said, "I just want to seek help and know where to go at each stage as I progress." And another proposed, "Doing it not just reading about how to do it."

Two-thirds of participating librarians reported they had past or current collaborative research experience, with either colleagues or interdisciplinary teams, and the benefits they gained from them were motivation, experience, and confidence. Almost all respondents expressed interest in future collaborative arrangements, suggesting various mechanisms for fostering them, such as creating "an online collaborative research matrix" for sharing project ideas, preparing a "landscape overview" of collection research interests and capacity, developing a research bibliography, and perusing the repository.

At the same time, participating librarians were equally as interested in formalized research mentoring as they were in collaborative research opportunities, although far fewer (15\%) noted prior experience with formal mentorships. A cautionary note was registered by several respondents around the complexities of mentoring, with a strong preference expressed for voluntary relationships and for requisite mentor qualifications, namely that they should have recent research and publishing experience; and, as one respondent said, that relationships should be "centred around real projects, that is, not just a go-for-coffee-stareat-each-other-because-you-don't-evenknow-where-to-start type of thing."

Many respondents commended the university library for the existing range of research supports designed to foster further research and promote an institutional climate of research and scholarly work. As one respondent observed, "We have come a very long way in the past 
5 years. I would say that the culture of research and scholarship is already well established. Time is always scarce. We are doing about as much as possible within the agreed on $15-20 \%$ time commitment to scholarly work and the occasional sabbatical."

These respondents offered the view that the array of supports already in place was more than adequate for integrating research into the organizational culture, citing:

- a university start-up research grant of up to $\$ 5,000$;

- University Research Office advice on writing grant proposals (such as for SSHRC);

- the Accountable Professional Expense Fund allowance of $\$ 2,000+$ annually;

- the Dean's Research and Innovation Fund of approximately $\$ 6,000$ per fiscal year;

- the Dean's Research Lecture series;a bookable research room (but the question was raised of how well used it is, and one respondent noted they needed to make better use of it to be alone and get away from office distractions);

- explicit recognition in the Guidelines for the Assignment of Duties for time for research $(15 \%$ for tenured librarians, $20 \%$ for probationary librarians, plus an option for pretenure librarians of $100 \%$ assignment to research and scholarship for a specific period leading up to renewal or tenure);

- the Librarians' Forum, which is evolving into a good discussion group for research-related issues and emerging research interests;modeling by the Dean;

- workshops and lectures on research methods;

- advertisements for new librarians that include an explicit research expectation;

- sabbaticals;

- support for librarians wanting to improve their education and knowledge at the graduate level, especially those pursuing doctoral qualifications.
At the same time, respondents offered a plethora of ideas for enhancing research activities, research engagement, and the research culture, with themes clustering around either managerial communication to clarify existing institutional policies and practices, or issues concerning the librarians themselves in their individual and social contexts as researchers. Key themes were:

- work level issues, research time guidelines, and time management;

- the reward system related to singleauthored research output and focused on peer-reviewed journal articles;

- research support for new librarians;

- individualized research support;

- point-of-need guidance and opportunities for sharing, communication, and learning about research;

- mentorship, primarily informal;

- individual Web pages for librarians to increase visibility, enhance their collective image as researchers to the wider campus community, and initiate collaborative research partnerships.

Still, a few respondents expressed skepticism and reservations about the university library's research expectations and priorities, proposing that research should be only for those who want to be involved. One respondent indicated feeling unprepared for life as an academic as opposed to service provider. Another observed, "For some of us, the research component of our job feels like a square peg in a round hole.... I worry about the long-term impact on retention."

However, the survey findings revealed generally positive attitudes and ideas by the majority of respondents: in particular, endorsing the present institutional vision and direction, and also expressing optimism about additional support and learning opportunities that might be expected to result from the needs assessment project.

\section{Conclusions}

While there has long been a subjective, impressionistic sense that University of 
Saskatchewan librarians were professionally active in research and scholarship, this survey provides strong evidence of their engagement at very high levels. The survey also helps to shed light on their self-identified educational needs for more research knowledge in key areas.

Three clusters of recommendations were made with a view to supporting and fostering the current institutional research vision and direction, and encompassing an array of overlapping and interconnected opportunities for action:

1. continuance and enhancement of current university library policies and practices;

2. pathways to institutionalize collaboration at broader levels; and

3. strategies to foster and support librarians' continuous research learning, together with mechanisms to facilitate collegial interactions and internal communication about research and scholarly communication.

In summary, it was anticipated that, over the medium term, the recommended initiatives taken together would serve to build the research confidence and productivity of librarians as faculty, and thereby intensify the research profile of the university library within and beyond the University of Saskatchewan. A worthwhile initiative would be a follow-up study five years hence to serve both as an assessment of progress and as an assessment of the value of the frameworks and recommendations suggested in the 2010 survey.

This study has stimulated broader institutional policy questions. How is a climate of research and scholarship achieved? What are the essential elements of a strong research culture? How can this culture be fostered, and by whom? What are the barriers to research and research productivity? Some implications for identifying best practices come out of the UAL needs assessment in part, but corroborated and expanded through experience, the literature, and colleagues. One goal might be to draft a template of best practices for fostering a research culture at individual institutions.

Some key factors can be identified in enhancing an organizational culture of research and scholarship. They pertain broadly to policies, strategies, and practices for research and scholarship. One place to start in thinking about these issues is to identify the multiple stakeholders and constituencies involved, among whom are:

- university administration;

- library administration;

- librarian cohort and peers in other institutions;

- user communities;

- faculty as collaborators and resource persons;

- university research grants and research ethics offices;

- institutional, professional, and related associations;

- professional journals and other professional publishing venues.

In conclusion, given the emergence in the University of Saskatchewan Library survey of patterns somewhat similar to those described in the University of Alberta Libraries study (Schrader 2010, 2011), the question is prompted of whether these findings can be taken as generally suggestive of configurations across those Canadian academic libraries committed to promoting and supporting an institutional culture of research engagement and scholarly communication among their cohorts of professional librarians. While the University of Saskatchewan Library survey project is indicative as a case study, the broader hypothesis awaits testing not only in other institutions and at the national level, but in other countries as well. In the meantime, the survey findings reported here will help to advance the research and knowledge production agenda of the University of Saskatchewan Library. 


\section{Appendix A \\ "Section 5.2 Scholarly Work," excerpted in full from the University of Saskatchewan Library Standards for Promotion and Tenure (rev. April 24, 2003), pp. 5-6: “5.2 Scholarly Work}

Research, scholarly and/or artistic work is creative, intellectual work which is in the public realm and which has been subjected to external peer review. Publication in reputable peer-reviewed outlets is the primary evidence in this category.

Scholarly work is expected of all librarians. Unlike traditional faculty research, a librarian's scholarly work usually derives from professional practice. Candidates for tenure or promotion will engage in scholarly work appropriate to academic librarianship with the fundamental expectation that the results of scholarly work will be shared with other members of the profession and the academic community. A librarian's scholarly work may be in one or more but not necessarily all of the following areas:

a. applied scholarship: investigations of the practice within the library environment. Covers such areas as library organization and management practices, application of new technology, development of information delivery methods and services, application of teaching methods, development of standards for organizing information and library resources.

b. subject scholarship: research in the literature of specific disciplines resulting in the publication of bibliographies, resource lists, internet site evaluations, translations, books, articles, etc.

c. theoretical/policy scholarship: exploration of issues leading to the development of theory, policy and standards of practice for the library community. For example: copyright for digital resources, electronic licensing agreements, equity and sustainability of information access.

The appropriate vehicles for dissemination of scholarly work will include one or more of the following peer reviewed outlets:

i. articles in scholarly journals;

ii. books, chapters in books;

iii. technical reports/reports to agencies derived from research;

iv. presentations at academic, scientific or professional meetings;

v. editorial work;

vi. substantial translation work;

vii. curated exhibits.

External peer validation of scholarly work is also derived from evidence of the adoption, implementation or replication of a librarian's work on policy, practice, technological developments or library services by others in the extended library community.

Evaluation of scholarly work for tenure and promotion at all ranks will address the quality and significance of the work, not simply the amount. In addition, there must be a positive indication of continuing involvement in scholarly work." 


\section{Appendix B \\ Summary of Responses to the Web-enabled Questionnaire Survey $(\mathrm{N}=30)$}

1. Please describe the area or program of research, broadly defined, in which you are interested at present. If neither, please elaborate. ( $n=27$, multiple responses)

2. Are you currently involved in a research project? $(n=29)$

\begin{tabular}{|c|c|c|c|c|c|c|}
\hline Yes & 19 & $66 \%$ & & & & \\
\hline No & 10 & $34 \%$ & & & & \\
\hline
\end{tabular}

3. Do you have any plans, within the next year or two, to complete a research project and present the results at a conference session or workshop, on a panel, in a poster session, in a journal (paper or digital), as a book or book chapter, or in some other way? $(n=29)$

\begin{tabular}{|c|c|c|l|l|l|l|}
\hline Yes & 27 & $93 \%$ & & & & \\
\hline No & 2 & $7 \%$ & & & & \\
\hline
\end{tabular}

4. What research experience have you had in the last two years? $(n=27$, multiple responses)

\begin{tabular}{|l|c|}
\hline journal article (digital or paper format) & $59 \%$ \\
\hline conference or workshop presentation or panel & $59 \%$ \\
\hline conference organizer & $33 \%$ \\
\hline research grant proposal & $26 \%$ \\
\hline poster presentation at a conference or workshop & $22 \%$ \\
\hline digital publication, e.g., wiki, database, website & $18 \%$ \\
\hline book review & $18 \%$ \\
\hline journal editor or referee & $18 \%$ \\
\hline paper in conference proceedings & $11 \%$ \\
\hline book & $11 \%$ \\
\hline book chapter & $7 \%$ \\
\hline conference proceedings editor & $4 \%$ \\
\hline
\end{tabular}

other: evidence summaries; journal column; digital edition of a project; conference session write-up for a journal; internal research reports; book reviews as well as some journal articles about a service innovation, "but I would not consider these publications to be research".

5. How would you describe your own knowledge of research and the research process? $(\mathbf{n}=27)$

\begin{tabular}{|l|l|l|}
\hline a bit uncertain, feel I need an introduction to ... & 7 & $(26 \%)$ \\
\hline
\end{tabular}




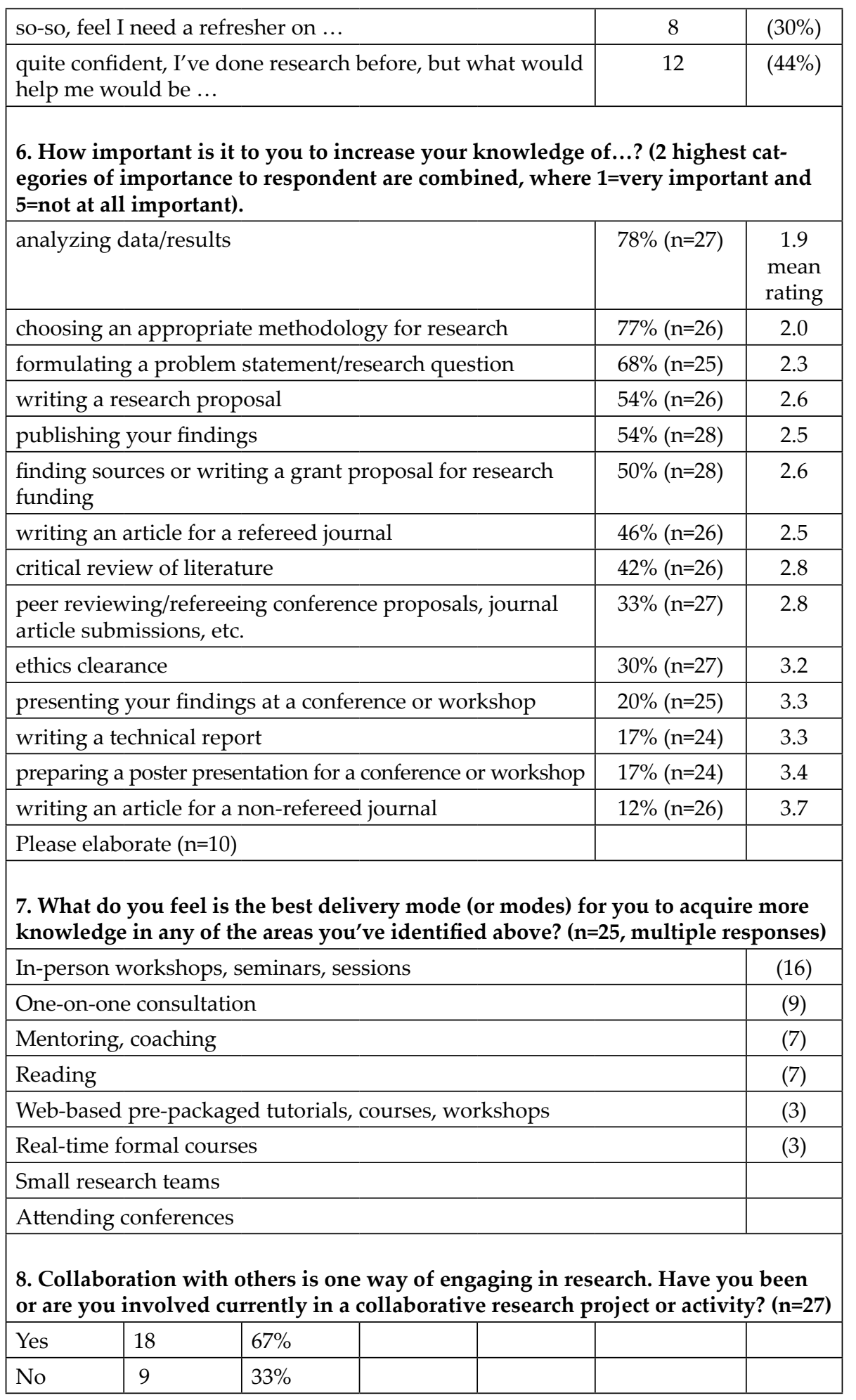




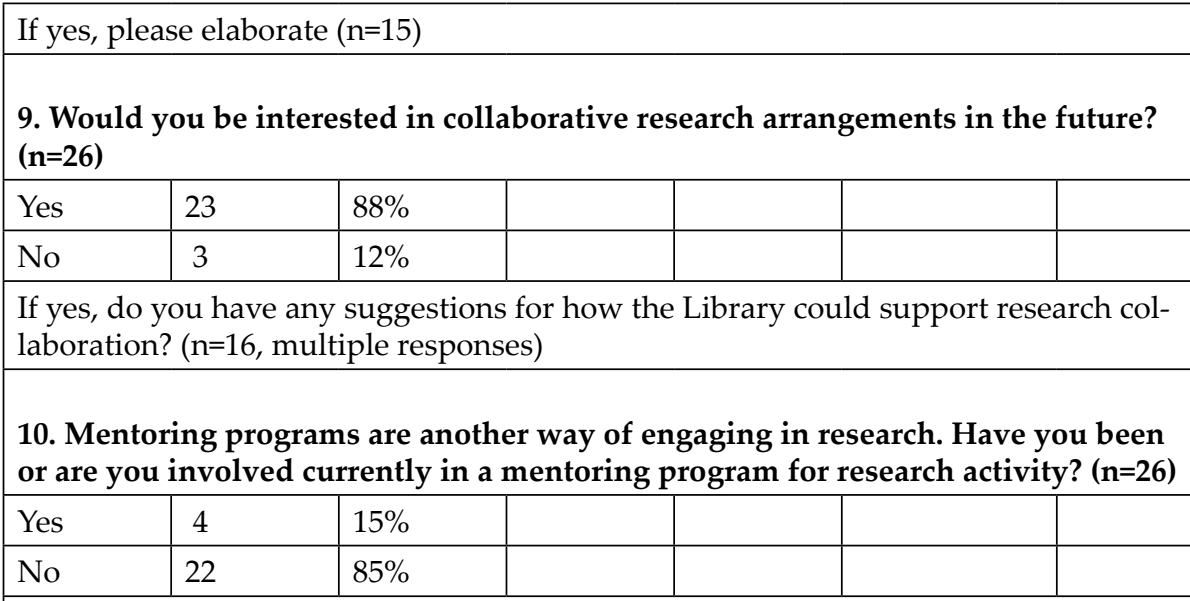

11. Would you be interested in participating in such a mentoring program in the future? ( $n=23)$

\begin{tabular}{|l|l|l|l|l|l|l|}
\hline Yes & 22 & $96 \%$ & & & & \\
\hline No & 1 & $4 \%$ & & & & \\
\hline
\end{tabular}

If yes, do you have any suggestions for how the Library could support mentoring? $(\mathrm{n}=14)$

12. What types of research supports do you think the Library should provide for your research activities and to promote a culture of research and scholarly work? $(\mathrm{n}=22)$

13. Do you have any other comments that would help the Library support your research engagement? $(n=12)$

14. Do you have any other comments? $(n=8)$

\section{Notes}

1. Regna Darnell, "Research Excellence at Western," Faculty Times: A UWOFA Newsletter (Oct. 2009): 7-8.

2. Elizabeth Church, "A Researcher's Journey Begins with the Smallest Steps" [Interview with Ellen Bialystok], Globe and Mail (Apr. 14, 2010): A3.

3. Canadian Association of Research Libraries, "CARL Strategic Plan Directions 2010-2012" (Media release Nov. 11, 2009), available online at www.carl-abrc.ca/about/strategic_plan_20102012-.html [accessed 1 March 2010]; “Core Competencies for 21st Century CARL Librarians" (2010), available online at www.carl-abrc.ca/resources/reports_and_briefs/pdf/core_comp_profile-e.pd [accessed 1 April 2010].

4. Vicki Williamson, "CARL Questionnaire Results" (unpublished study, 2010).

5. Canadian Association of University Teachers, "Issues \& Campaigns: Librarians \& Libraries" (2009), available online at www.caut.ca/pages.asp?page=219 [accessed 6 April 2010].

6. Canadian Association of University Teachers, "Model Clause on the Scholarly Activities of Academic Librarians," CAUT Council, May 2003, available online at www.caut.ca/pages. asp?page=412\&lang=1 [accessed 6 April 2010]. 
7. Daphnée Rentfrow, "Groundskeepers, Gatekeepers, and Guides: How to Change Faculty Perceptions of Librarians and Ensure the Future of the Research Library," in No Brief Candle: Reconceiving Research Libraries for the 21st Century (Washington, D.C.: Council on Library and Information Resources, Aug. 2008), 64.

8. University Library, University of Saskatchewan, University of Saskatchewan Library Strategic Plan (Sept. 2009), 12.

9. University of Saskatchewan, The Second Integrated Plan: Toward an Engaged University 2008/09-2011/12 (May 2008), 16-19, available online at www.usask.ca/ip/inst_planning/docs/ UofS_Report_Booklet_final_LR.pdf [accessed 11 March 2010].

10. Jacalyn E. Bryan, "The Question of Faculty Status for Academic Librarians," Library Review 56 (2007): 781.

11. Catherine Coker, Wyoma vanDuinkerken, and Stephen Bates, "Seeking Full Citizenship: A Defense of Tenure Faculty Status for Librarians," College and Research Libraries 71 (Sept. 2010): 406.

12. Donald E. Riggs, "Faculty Status for Librarians: Force-Fitting into an Inappropriate Mold or Not?" College and Research Libraries 60 (July 1999): 306.

13. Bryan, "The Question of Faculty Status," 782, 785.

14. Ibid., 782.

15. Association of College and Research Libraries, "Guidelines for Academic Status for College and University Librarians," College and Research Libraries News 68 (June 2007): 378-79.

16. Association of College and Research Libraries, "A Guideline for the Appointment, Promotion and Tenure of Academic Librarians," College and Research Libraries News 71 (Nov. 2010): $552-60$.

17. Deborah B. Henry and Tina M. Neville, "Research, Publication, and Service Patterns of Florida Academic Librarians," The Journal of Academic Librarianship 30 (Nov. 2004): 435.

18. Paul Alan Wyss, "Library School Faculty Member Perceptions Regarding Faculty Status for Academic Librarians," College and Research Libraries 71 (July 2010): 376.

19. Ibid., 379, 383.

20. Alvin M. Schrader, “The Three Cultures of Librarianship: A Personal Odyssey through Education, Research and Service," Bibliotheca Medica Canadiana 24 (fall 2003): 171.

21. Joseph Fennewald, "Research Productivity among Librarians: Factors Leading to Publications at Penn State," College and Research Libraries 71 (Mar. 2008): 104-16.

22. David Fox, "Finding Time for Scholarship: A Survey of Canadian Research University Librarians," portal: Libraries and the Academy 7 (2007): 451-62; David Fox, "The Scholarship of Canadian Research University Librarians," Partnership: The Canadian Journal of Library and Information Practice and Research 2 (2007): 1-24.

23. Alvin M. Schrader, "Fostering a Research Culture in Canadian Academic Libraries," in Resources from Super Conference 2010, Ontario Library Association, available online at www.accessola2.com/superconference2010/thu/332/schrader.pdf [accessed 4 April 2010]; Alvin M. Schrader, "Exploring the Research Knowledge Needs of Canadian Academic Librarians." In New Trends in Qualitative and Quantitative Methods in Libraries: Selected Papers Presented at the 2nd Qualitative and Quantitative Methods in Libraries. Proceedings of the International Conference on QQML 2010, Chania, Crete, Greece, 25-28 May 2010, eds. Anthi Katsirikou and Christos Skiadas. Singapore: World Scientific, 2012, pp. 297-306.

24. Phillip M. Edwards, Elaine Z. Jennerich, and Jennifer L. Ward, "Supporting a Culture of Library Research at the University of Washington at Seattle," in An Introduction to Staff Development in Academic Libraries, ed. Elizabeth Connor (New York: Routledge, 2009), 80-85.

25. Kristine Brancolini and Marie Kennedy, "Library Research Survey: Informed Consent" (Web questionnaire survey), available online at http://library.lmu.edu/departments/acquisitions_serials/ Informed_Consent.htm [accessed 14 December 2010].

26. Henry and Neville, "Research, Publication, and Service Patterns of Florida Academic Librarians."

27. Brancolini and Kennedy, "Library Research Survey: Informed Consent." 